\title{
Bangladesh National Drug Policy 1982-2016 and Recommendations in Policy Aspects
}

\author{
(1) Munzur E Murshid ${ }^{1}$, (1) Mainul Haque ${ }^{2}$ \\ 1Public Health Improvement Initiative in Rajshahi, Development Association for Self-reliance Communication and Health, Sapahar Upazila Health \\ Complex, Sapahar, Naogaon, Bangladesh \\ 2Unit of Pharmacology, Faculty of Medicine and Defence Health, Universiti Pertahanan Nasional Malaysia (National Defence University of Malaysia), Kem \\ Sungai Besi, Kuala Lumpur, Malaysia
}

\begin{abstract}
Science is progressing a lot in recent years. Remarkable advances have been achieved in the field of health care technology. However, unfortunately, medicines are still the only hope for treating diseases for thousands of people in developing countries around the world. An effective National Drug Policy might be a lifesaving step for many people in these countries. Fortunately, that happened in Bangladesh after the 1982 Drug Policy. In the meantime, the country has further editions of that policy, which were National Drug Policy 2005 \& 2016. In this article, this research will discuss the comparative impact scenario of these policies in Bangladesh. Readers will know the past and present of the National Drug Policy of Bangladesh and will be able to assume the future of this policy in Bangladesh.
\end{abstract}

Keywords: Bangladesh, National Drug Policy, 1982, 2005, 2016

\section{Introduction}

This study used the search terms "National Drug Policy (NDP), Bangladesh", "NDP Bangladesh", "Bangladesh National Drug Policy" etc. for searching in PubMed and Google scholar search engine for the literature review. Researchers also collected information from different books collected from Bangabandhu Sheikh Mujib Medical University, National Institute of Preventive and Social Medicine, Gonoshasthaya Kendra library of Dhaka, Bangladesh.

\section{National Drug Policy}

The World Health Organization (WHO) defines NDP as "a comprehensive framework in which each component plays an important role in achieving one or more of the general objectives of the policy (access, quality, and rational use)" (1). The policy must have the self-assurance of the several penalty area and purposes, generating a comprehensive and reliable existence. The system should address access to essential medicines (EMs).
Essential medicine was defined in 1977 as "medicines that are of utmost importance, and are basic, indispensable and necessary for the health needs of the population" (2). In 2002, EMs were again redefined as "EM are those that satisfy the priority health care needs of the population. They are selected with due regard to public health relevance, evidence of efficacy, safety, and comparative cost-effectiveness. EM are intended to be available within the context of functioning health systems at all times in adequate amounts, in the appropriate dosage forms, with assured quality and adequate information, and at a price the individual and the community can afford. The implementation of the concept of EMs is intended to be flexible and adaptable to many different situations; exactly which medicines are regarded as essential remains a national responsibility" (2). It is often explained that such access to EM could be achieved through the promotion of rational use of medicines (RUM), reasonable prices, workable sponsoring, and consistent health and supply systems. Similarly, RUM depends on various issues, such as the careful and scientific selection of medicines, regulatory procedures, informative and
Corresponding Author: Mainul Haque, Professor of the Unit of Pharmacology Faculty of Medicine and Defence Health Universiti Pertahanan Nasional Malaysia (National Defence University of Malaysia) Kem Perdana Sungai Besi, 57000 Kuala Lumpur, Malaysia Phone: +60109265543 E-mail: runurono@gmail.com ORCID ID: orcid.org/0000-0002-6124-7993

Cite this article as: Murshid ME, Haque M. Bangladesh National Drug Policy 1982-2016 and Recommendations in Policy Aspects. Eurasian J Emerg Med. 2019;18(2):104-9.

(C) Copyright 2019 by the Emergency Medicine Physicians' Association of Turkey Eurasian Journal of Emergency Medicine published by Galenos Publishing House.
Received: 07.01.2019 Accepted: 14.05.2019 
educational interventions, and financial enticements (1). A NDP has also been described as "an assurance to an objective and an escort for a struggle to ensure the rights of the people". The NDP states the medium- to long-term goals of the national government for the pharmaceutical industries and ascertains the principal line of attack for achieving the aims. It offers an outline in which the accomplishments of the pharmaceutical sector can be synchronized. The NDP deals with both public and private segments of pharmaceutical issues and comprises all the notable thespians of this medicine-producing arena (3).

\section{Why Does the Country Need a National Drug Policy?}

Medicines play the most critical role in the care, protection, and reestablishment of the health of the citizens of any country. All governments around the world are highly concerned about the availability of medicines with appropriate quality, adequate amounts and in affordable price for ordinary people especially in low and middle-income countries (LMIC) (4-6). There are reports of irrational prescribing and drug use with poor availability of EMs, particularly in LMIC, and this also applies to poorer communities of the developed world (7-10). Moreover, about $90 \%$ of citizens of developing and emerging countries obtain medication from their out-of-pocket expenses when compared to developed nations $(11,12)$. Thereafter, the most important requirements for a NDP are to present different government commitments, to define pharmaceutical sector goals and objectives, to identify priority areas of action, to identify national strategies to achieve national goals, to identify stakeholders of implementation and finally to organize a national forum of discussion on the priority issues (3).

\section{According to WHO, the General Objectives of a National Drug Policy are to Ensure}

- Access: equitable availability and affordability of EMs.

- Quality: the quality, safety, and efficacy of all medicines.

- Rational use: the promotion of a therapeutically sound and cost-effective method of drugs by health professionals and consumers $(1,13)$.

\section{National Drug Policy of Bangladesh}

Bangladesh won its independence on December 16, 1971. During the birth of the country, the socio-economic infrastructural situation was fragile. Before independence, it was reported that 60-70\% of drugs were imported from West Pakistan, because most of the pharmaceutical industry were mainly located in the western part of Pakistan (14). After independence, it became a great challenge for the Government of Bangladesh to ensure the availability and accessibility of EMs. Despite this crisis due to lack of drug policy, the market was full of unnecessary drugs. The plight of EMs was first critically identified in the country's first five-year plan in 1973 (14). After this blueprint, multiple industries started importing finished medicine products on a large scale that were packaged and marketed locally in Bangladesh. These local industries were actually representing and acting for some overseas pharmaceutical companies. Additionally, poor quality control was observed, mainly for drugs with doubtful efficacy and counterfeit medicine (15). The country has gone through several stages of policy development programs for drug policy, which ultimately delivered a deep-seated, comprehensive, publicfriendly NDP in 1982, as the effort made in 1973 did not work efficiently (16-18). The honorable attempt in 1973 to formulate the drug policy to improve the situation failed due to the tragic assassination of the country's father of the nation and President Bangabandhu Sheikh Mujibur Rahman in 1975 (15).

\section{Bangladesh National Drug Policy 1982}

Bangladesh NDP 1982 is an epoch-making event in the history of Bangladesh. Before 1982, there was no NDP in Bangladesh (19). The medicine market in Bangladesh was filled with unnecessary, harmful, and unsafe medicines before NDP 1982 and multinational companies were controlling the pharmaceutical markets of Bangladesh $(17,20)$. Only 14 countries, including Bangladesh, had NDP in 1982 (21,22). On April 27, 1982, an expert committee was formed. Expert Committee consisted of renowned academicians, regulatory personnel, and health activists (23). Bangladesh NDP 1982 was highly praised by WHO and other international organizations at that time $(15,20)$. After that, the glory of Bangladesh has increased in relation to the policy (13).

\section{The Work (Report) of the Expert Committee}

A highly knowledgeable, proficient and professional commission was formed to develop NDP. This commission worked very methodically, spending over 1000 business hours to build the policy, which was tabled to the Ministry of Health on the auspicious day May 11, 1982 (15).

This commission undisputedly formulated 16 principles to appraise all currently available medical, medicinal, pharmacological and therapeutic products, and new drugs applied for cataloging or approved (15).

\section{The Sixteen Principles}

1. The combination of antibiotics will be prohibited. The combination of antibiotics with glucocorticoid or other similar active ingredients will be banned. Harmful liquid forms of antibiotics (e.g., tetracycline) will be banned. Tetracycline may hamper bone growth and may cause discoloration of teeth of a child. Combinations of antibiotics have no therapeutic advantage; instead, it promotes more adverse effects. 
2. The combination of analgesics will be prohibited. The combination of analgesics with iron, vitamins, or alcohol will also be banned. Analgesic combinations promote adverse events, and their therapeutic value is dubious in nature. Another problem in combination medicine is if a dose adjustment is required in case of any single or multiple elements, then it would be impossible as the components remain is fixed strength in combination forms.

3. Due to the risk of addiction or dependency, any combination form of codeine will not be allowed.

4. In general, combinations can be allowed if there is absolutely no alternative single drug available for treatment or if no alternative single drug is cost-effective, for the purpose.

5. Certain exceptions will be made in the cases of eye, skin, respiratory and hemorrhoidal preparations, co-trimoxazole, oral rehydration salts, antimalarial, iron-folic, etc., as well as certain vitamin preparations, allowing combinations of more than one active ingredient in one product.

6. Vitamins must be formulated as a particular/individual component products, except for B complex. B12 should always be produced as a single-ingredient injectable product. The combining of Vitamins with any other ingredient such as minerals, glycerophosphate, etc., will also be prohibited. The liquid form of vitamins was prohibited in order to prevent the wastage of resources used to produce liquid vitamins, because it has no beneficial impacts on health.

7. Cough syrups, throat pastilles, gripe water, alkalis, and etc. production will be prohibited due to their questionable scientific efficacy.

8. The sale of tonics, enzyme mixtures/preparations, and alleged recuperative and invigorating products should be discontinued. However, pancreatin and lactase may be manufactured and/or imported as single-ingredient products. Tonics were prohibited because there was a significant amount of alcohol in tonics that may cause addiction or dependency.

9. Me-too drugs will not be allowed. Me-too drugs are those drugs that have the same or almost the same efficacy but have nonsignificant structural dissimilarity.

10. Medicine with uncertain, petite or no healing and beneficial significance, and to a certain degree, from time to time detrimental, dangerous for human health, and often increases the possibility of misuse, will be debarred and proscribed.

11. All prescription chemicals and galenical preparations, which are included in the latest edition of the British Pharmacopeia or the British Pharmaceutical Codex, will be approved.
12. Considering the favorable risk: benefit ratio; certain medicine, despite known severe adverse effects and the possibility of misapplication, may be manufactured in a small amount for limited and regulated use. These medicines will be prescribed by medical specialists only.

13. The medicines, which can be produced by national medicine industry, should not be imported in order to protect the medicine industry of Bangladesh. However, if local production is far short of need, this condition may be relaxed in some cases.

14. A primary pharmaceutical raw material, which is locally manufactured, will be given protection by disallowing it or its substitute to be imported if sufficient quantity is available in the country. The role of multinationals in providing medicine for this country is acknowledged with appreciation. In view of the caliber of machinery and technical know-how which lies in their hands for producing important and innovative drugs for the country. Easily producible drugs such as antacids and vitamins will be produced by only national companies. So that the large transnationals and corporations can focus their energies and capitals on those medicines not so straightforwardly manufactured by smaller domestic pharmaceutical industries.

15. Foreign brands were not allowed to manufacture under authorization in any pharmaceutical industry in Bangladesh if the identical or comparable medicines are existing/manufactured in Bangladesh, as this leads to superfluously high prices and imbursement of royalties. In the light of this policy, all existing licensing agreements should be reviewed.

16. According to the policy, "Third Party Licensing" will not be allowed. Under the third party licensing a company can manufacture and distribute drugs in the market.

The first eleven principles were established completely on scientific perceptive, although, the Principle 14 was based on political and economic thoughts. The remaining four principles $(12,13,15$, and 16) were considered for the assistance and growth of the homegrown, domestic pharmaceutical manufacturing plant. There were 166 approved medicinal and therapeutic products available in Bangladesh during the development and promotion of NDP-1982. Interestingly, 122 multinational pharmaceutical industries were exporting medicines to the country from 23 countries. Additionally, 4,340 medicinal products were approved. These products were either produced locally or imported. The commission banned 1,742 medicinal products by utilizing 16 principles of NDP-1982, as these medicines were either ineffective or non-essentials.

These banned 1,742 medicines were placed in one of three categories (15): 
Schedule I: Production of these drugs was to be stopped immediately and stocks were to be collected from pharmacies and destroyed within three months of the acceptance of the report.

Schedule II: These drugs were to be reformulated within six months on the basis of the guidelines suggested by the committee.

Schedule III: A maximum of nine months was allowed for using up stocks of these drugs.

Importation of raw materials for Schedule I and II drugs was prohibited (15).

\section{Significant Recommendations of NDP-1982 (15)}

1. Establish an essential list of 150 EMs and a supplementary list of 100 specific drugs. The basic list was subdivided into three levels of use: 12 drugs for village workers; 45 medications for primary health care; and all 150 drugs for tertiary care,

2. Use generic names for the manufacture,

3. Prepare and publish a National Formulary by 1983,

4. Eliminate product patents and limit the use of process patents,

5. Revise the 1940 Drugs Act to include:

a. A registration system for Ayurvedic, Unani and homeopathic medicines;

b. Implementation of good manufacturing practices (GMP), together with ample quality control;

c. Regulating labeling and promotional activities;

d. Price control;

e. Prescription control of toxic/poisonous and abusing medicine;

f. Establishing of specialized medicine courts and substantial punishments;

g. Regulation of technology transfer and licensing agreements with foreign collaborators;

h. Restriction of ownership of retail pharmacies to professional pharmacists only;

6. Set up a National Drug Control Laboratory by 1985 ,

7. Commission report advised to ban multinational pharmaceutical industry from manufacturing simple medicine like common analgesics, vitamins, antacids,

8. All public hospitals should institute registered retail pharmacies under the supervision of qualified pharmacists,
9. Strengthen the Drug Administration administrative capacity by educational interventions among drug inspectors up to the lowest public administrative level of the country (15).

\section{Impacts of National Drug Policy 1982 (16)}

1. Local production of allopathic, traditional and complementary alternative drugs increased substantially.

2. Availability of EMs also increased remarkably with the increase in the volume of local production of all types of recognized drugs, the monetary value of which grew from Taka 1730 million in 1981 to about Taka 41000 million in 2002.

3. Local companies increased their production share from $30 \%$ in 1970 to more than $80 \%$ in 2002.

4. Drug prices stabilized, increasing (practically a drop-in cost in real times) by only $20 \%$, compared to an increase of $179 \%$ in the consumer price index. This made drugs more affordable to consumers.

5. The quality of the products was improved, and the proportion of substandard drugs fell from 36\% in 1970 to just 2\% in 2002.

6. The volume of imported drugs and medicine in the country reduced drastically.

7. Commendable progress occurred in the research, education, and manufacturing of Unani, Ayurvedic, and HomeopathicBiochemic systems of medicine.

8. The less dependency on imports and prioritization of useful drugs saved the country approximately US\$600 million every year.

9. Bangladesh, a drug importing country, has become a drug exporting country (16).

According to NDP-1982, producers were compelled to produce EMs. There was a specific instruction that $60 \%$ of their total production would be EMs and price of EMs were fixed by the Government of Bangladesh. The cost of medicine depends on elements of expenditure on production and other factors. During the 1982 policy, experts considered five categories of elements of expenditure to fix up the price of EMs. NDP-1982 has effectively ended to transfer pricing and over-invoicing for imports of capital machinery, raw materials, and packaging materials. Without scientific evidence, combination of drugs was strictly prohibited in NDP-1982. Transnational Companies were strictly prohibited from producing medications that can be produced with more accessible technology. It was implemented according to NDP-1982 to promote the growth of national pharmaceutical market $(15,24,25)$. 


\section{National Drug Policy 2005}

Price protection was relaxed in Bangladesh by NDP-2005 $(26,27)$. Afterward, the pharmaceutical owners and manufacturers took the opportunity to increase the prices of medicines, including EMs, to maximize their profit. Moreover, drug pricing in middle, and low-income countries is an essential and antagonistic issue. Since most patients do not have or cannot afford any insurance coverage and need to pay in person for their medicine, pricing proportionate with income status is significant to bear the cost (28). The third-party licensing restriction was relaxed to encourage the expansion of the pharmaceutical industry. The national companies started facing a tremendous challenge. NDP-2005 committee consisted of mainly pharmaceutical industrialists. The Committee focused principally on expanding their business without considering safety, efficacy, and affordability of EMs. There were no specific obligations regarding EMs production (27). Also, there were no special instructions regarding EMs pricing in NDP-2005 (27). Similarly, there was no clear-cut direction regarding combination drugs in NDP-2005, but the combination drugs were banned in NDP-1982 except for an exceptional need (27). In 1995, the government made a list of 117 EMs by a special communiqué. This meant that 33 type of EMs remained out of the EMs list and these drugs became open to price increases by the pharmaceutical industries. There were no specific instructions on the prohibition of production of medicines that could easily be produced by national companies in NDP-2005. There were no clear instructions regarding combination drug production in NDP-2005. Nevertheless, policymakers argued that if any combination medicine could be used in developed countries, then it could enter into national drug market. Finally, it can be concluded that the purity of NDP-1982 was destructed by NDP-2005 $(14,23)$.

\section{National Drug Policy 2016}

In NDP-2016, Bangladesh government made a list of priority medicines consisting of 285 medicines $(29,30)$. It also included ayurvedic, herbal, and homeopathic medicines. It was not a scientifically sound decision. NDP-2016 discourages registration of combination drugs. However, there is no clear-cut restriction on the production of combination drugs. There are no specific restrictions in NDP-2016, on not including pharmaceutical industrialists in the policy revision committee (27).

\section{A Few Recommendations for Improving the Situation}

Bangladeshi consumer needs to be aware of availability, accessibility, safety, and the efficacy of EMs for the successful implementation of an NDP. A community awareness campaign can be initiated to create community demand. To ensure good manufacturing practice, "Directorate of Drug Administration" should be strengthened by providing manpower, adequate lab facilities, commanding and administration power and financial resource flow, so that they can perform sustainably. We can reinforce our "Essential Drug Company Limited" by proving adequate manpower and logistics. Routine update list of EMs by "Expert Committee" consists of scientists, pharmacologists, and economists. Implementation of strict price controlling mechanism by the Government of Bangladesh is required. Currently, Bangladesh imports $80-90 \%$ active pharmaceutical ingredients, and it is the primary component that increases drug price in the country $(31,32)$. The country should produce APIs locally; otherwise, self-sufficiency will not be achieved.

\section{Ethics}

Peer-review: Externally peer-reviewed.

\section{Authorship Contributions}

Surgical and Medical Practices: M.E.M., M.H., Concept: M.E.M., M.H., Design: M.E.M., M.H., Analysis or Interpretation: M.E.M., M.H., Literature Search: M.E.M., M.H., Writing: M.E.M., M.H.

Conflict of Interest: No conflict of interest was declared by the authors.

Financial Disclosure: The authors declared that this study received no financial support.

\section{References}

1. World Health Organization. How to Develop and Implement a National Drug Policy. Second Edition. 2001. Available at http://apps.who.int/medicinedocs/ en/d/Js2283e/4.1.3.html [Accessed December 2, 2018]

2. World Health Organization. The selection and use of essential medicines. Report of the WHO Expert Committee, 2002 (including the 12th Model list of EMs). World Health Organ Tech Rep Ser. 2003;914:1-126.

3. World Health Organization. Making Drug Policy a Development Priority A Strategy Paper \& Six Country Stories. 1995. Available at: http://apps.who.int/ medicinedocs/en/m/abstract/Js19174en/ [Accessed November-16-2018]

4. Ahmadiani S, Nikfar S. Challenges of access to medicine and the responsibility of pharmaceutical companies: a legal perspective. Daru. 2016;24:13.

5. Hoebert JM, van Dijk L, Mantel-Teeuwisse AK, Leufkens HG, Laing RO. National medicines policies - a review of the evolution and development processes. J Pharm Policy Pract. 2013;6:5.

6. Kanji N, Hardon A, Harnmeijer JW, Mamdani M, Walt G. Drugs Policy in Developing Countries. London: Zed Books; 1992.p.136.

7. Frisher M, Martino O, Crome I, Croft P. Trends in drug misuse recorded in primary care in the UK from 1998 to 2005. J Public Health (Oxf). 2009;31:6973.

8. Mao W, Vu H, Xie Z, Chen W, Tang S. Systematic review on irrational use of medicines in China and Vietnam. PLoS One 2015;10:e0117710.

9. Ofori-Asenso R, Agyeman AA. Irrational Use of Medicines-A Summary of Key Concepts. Pharmacy (Basel). 2016:4.

10. Zaidi S, Bigdeli M, Aleem N, Rashidian A. Access to Essential Medicines in Pakistan: Policy and Health Systems Research Concerns. PLoS One. 2013;8:e63515. 
11. Cameron A, Ewen M, Ross-Degnan D, Ball D, Laing R. Medicine prices, availability, and affordability in 36 developing and middle-income countries: a secondary analysis. Lancet. 2009;373:240-9.

12. Kanavos P, Das P, Durairaj V, Laing R, Dele Olawale Abegunde DO. Options for financing and optimizing medicines in resource-poor countries. World Health Report (2010) Background Paper, No 34. Health System Financing. The Path of Universal Coverage. World Health Organization. 2010. Available at http:// www.who.int/healthsystems/topics/financing/healthreport/34Medicinesrev. pdf [Accessed December 2, 2018]

13. Chowdhury FR, Ahasan HA, Rahman MM. National Drug Policy of Bangladesh: Some Pitfalls in Implementation. J Coll Physicians Surg Pak. 2006;16:368-70.

14. Islam N. Purity Poisoned. 1st ed. Dhaka: Momin Offset Press, 2007.

15. Chowdhury Z. Bangladesh: A Tough Battle for a National Drug Policy. Available at: http://apps.who.int/medicinedocs/documents/s19176en/ s19176en.pdf [Accessed December 3, 2018]

16. Ministry of Health \& Family Welfare. Governments of Peoples of the Republic of Bangladesh. National Drug Policy 2005. Bangladesh Gazette, 440-453, 2005. Available at http://apps.who.int/medicinedocs/documents/s17825en/ s17825en.pdf [Accessed December 3, 2018]

17. Islam N. On a national drug policy for Bangladesh. Trop Doct. 1984;14:3-7.

18. Azam M. Intellectual Property And Public Health In The Developing World. Cambridge, UK: Open Book Publishers, 2016. Available at http://biblio. unibe.ch/download/eldiss/14azam_m.pdf [Accessed December 3, 2018]

19. Srinivasan S. 'Singing about the Dark Times': Bangladesh Drug Policy. Econ Polit Wkly. 1996;31:1252-5.

20. Reich MR. Bangladesh pharmaceutical policy and politics. Health Policy Plan. 1994;9:130-43.

21. Chowdhury FR, Bari MS, Khan MI. Implementation of National Drug Policy in Different Countries: An Appraisal and Experience from Bangladesh. J Bangladesh Coll Phys Surg. 2011;29:177-9.

22. Chowdhury FR, Muktadir MA, Chowdhury MA. National drug policy of Bangladesh 1982 \& 2005-effective implementation is must for peoples will (Bengali Article). Journal of Bangladesh Asiatic Society. 2007; 15 (Winter): 297-308. Available at https://www.researchgate.net/ publication/277662077_National_drug_policy_of_Bangladesh_1982_2005-
effective_implementation_is_must_for_peoples_will_Bengali_Article [Accessed December 4, 2018]

23. Chowdhury Z. The Politics of Essential Drugs. The Makings of a Successful Health Strategy: Lessons from Bangladesh. London: 1st ed. Zed Press; 1995.

24. Chowdhury N, Kabir ER. Per pill price differences across therapeutic categories: A study of the essential drug brands marketed by multinational and local pharmaceutical companies in Bangladesh. Afr J Mark Manage 2009;1:220-6.

25. Sarowar MG, Bhattarai N, Jain P, Bochenek T. The characteristics of the current drug policies in India, Nepal, and Bangladesh. Leki Za Granic $叉 2008$; 6 (1-2): 43-51. Available at http://www.ejournals.eu/sj/index.php/ZNOZ/ article/viewFile/5862/5784 [Accessed December 4, 2018]

26. Ministry of Health and Family Welfare, Bangladesh. National Drug Policy, 2005. Public Health Section-1. 2005. Available at http://www.clcbd.org/ document/download/53.html [Accessed on December 4, 2018]

27. Hamid SA. Drug Policy of 1982. The foundation of the industry was created. Special Number / Development Omnibus 2, Bonik Barta, 2018 [Accessed December 5, 2018]

28. Danzon PM, Mulcahy AW, Towse AK. Pharmaceutical pricing in emerging markets: effects of income, competition, and procurement. Health Econ. 2015;24:238-52

29. Directorate General of Drug Administration (DGDA), Ministry of Health \& Family Welfare. National Drug Policy 2016. DGDA. Ministry of Health \& Family Welfare, Bangladesh. Available at http://www.dgda.gov.bd/index. php/2013-03-31-05-16-29/guidance-documents/205-national-drug-policy2017-with-essential-drug-list-and-otc-list/file [Accessed December 4, 2018]

30. Tusher HJ. Updated drug policy Okayed by the cabinet. The Daily Star, 2016. Available at https://www.thedailystar.net/frontpage/cabinet-okays-updateddrug-policy-1332568 [Accessed December 4, 2018]

31. Muyeen NM. The growth of Pharmaceutical Company in Bangladesh. Bachelor's Thesis. Department of Pharmacy, Daffodil International University. Available at http://dspace.daffodilvarsity.edu.bd:8080/bitstream/ handle/20.500.11948/1866/P05743. pdf? sequence $=1 \&$ is Allowed $=y$ [Accessed on December 4, 2018]

32. Islam S, Rahman A, Al-Mahmood AK. Bangladesh Pharmaceutical Industry: Perspective and Prospects. Bang J Med Sci. 2018;17:519-25. 